\title{
KUESIONER PRA SKRINING PERKEMBANGAN (KPSP) BERBASIS ANDROID SEBAGAI MEDIA PEMBELAJARAN
}

\author{
Aulia Ridla Fauzi $\left.{ }^{*} 1\right)$; Neli Sunarniं ${ }^{2}$; Rosidah Solihah ${ }^{3}$ \\ 1, 2, 3 Prodi D3 Kebidanan; STIKes Muhammadiyah Ciamis \\ Jl. K. H. Ahmad Dahlan No. 20 ; Ciamis ; Kabupaten Ciamis
}

\begin{abstract}
Abstrak
Keterlambatan perkembangan anak pada masa emas terjadi karena kurangnya stimulasi pada otak. Salah satu instrumen deteksi dini perkembangan pada anak adalah kuesioner pra skrining perkembangan (KPSP). Pemantauan tersebut merupakan salah satu kewenangan Bidan. Selama ini, pengisian KPSP dilakukan secara konvensional dari lembaran formulir. Maka dari itu, diciptakan sebuah aplikasi KPSP berbasis android yang digunakan dalam proses pembelajaran mahasiswa. Tujuan penelitian ini merancang dan membangun format deteksi dini perkembangan (KPSP) berbasis android yang dipasang pada smartphone agar memudahkan mahasiswa dalam proses skrining. Desain penelitian ini adalah rancang bangun dengan pendekatan waterfall tahapan software development life cycle (SDLC) dan dianalisis menggunakan User Experiment Questionnaire (UEQ). Responden terdiri dari mahasiswa D3 Kebidanan semester 4 dan 6. Statistik data menunjukkan interpretasi seluruh komponen 50\% hasil yang baik/memuaskan dan 25\% lainnya tidak memuaskan. Empat komponen bernilai positif dari aplikasi KPSP diantaranya adalah daya tarik, kejelasan, efisiensi, dan ketepatan. Sedangkan komponen stimulasi dan kebaruan bernilai netral. Aplikasi KPSP perlu perbaikan pada aspek kebaruan, keterbatasan tampilan (user interface), isi, dan bahasa aplikasi ini perlu dimodifikasi agar lebih interaktif dan mutakhir sesuai dengan minat pengguna.
\end{abstract}

Kata kunci: Kuesioner Pra Skrining Perkembangan; Aplikasi Android;

\begin{abstract}
[ANDROID-BASED PRE-SCRINING QUESTIONNAIRE (KPSP) AS A LEARNING MEDIA] Developmental delays in the golden period occur due to a lack of stimulation of the brain. The developmental pre-screening questionnaire (KPSP) is an instrument for early detection. Monitoring is one of the midwives' authorities. So far, filling in the KPSP is done conventionally from a sheet of form paper. Therefore, a breakthrough was created by creating an Android-based KPSP application in the student learning process. Objective this study aims to design and build an Android-based developmental pre-screening (KPSP) format installed on smartphones to make it easier for students in the screening process. A research and development design with a waterfall approach to the stages of the software development life cycle (SDLC) and is analyzed using the User Experiment Questionnaire (UEQ). Respondents consisted of D3 Midwifery students in semesters 4 and 6. Statistical data shows the interpretation of all components $50 \%$ of the results are good/satisfactory and the other $25 \%$ are unsatisfactory. The four positive components of the KPSP application are attractiveness, clarity, efficiency, and accuracy, while the stimulation and novelty components are neutral. The KPSP application needs to be improving in terms of novelty, limited user interface, content, and the language of this application needs to be modified to be more interactive and up-to-date according to user interests.
\end{abstract}

Keywords: The Indonesian Child Development Pre-Screening Questionnaire; Android Aplication;

\section{Pendahuluan}

Pembangunan kesehatan sebagai bagian upaya membangun manusia seutuhnya, salah satunya adalah upaya kesehatan anak yang harus

*) Correspondence Author (Aulia Ridla Fauzi)

E-mail: auliaridlafauzi@gmail.com dilakukan sedini mungkin. Upaya kesehatan anak sejak mulai dalam kandungan sampai lima tahun pertama kehidupan ditujukan untuk mempertahankan keberlangsungan hidup dan meningkatkan kualitas hidup anak supaya mencapai tumbuh kembang yang optimal baik fisik, mental, emosional maupun sosial. Masa 
lima tahun pertama kehidupan merupakan masa yang sangat peka terhadap lingkungan atau dikenal dengan golden period, window opportunity dan critical period, masa ini berlangsung sangat pendek dan tidak terulang (Kemenkes RI 2016).

Hasil penelitian menunjukkan $16 \%$ anakanak mengalami masalah perkembangan, deteksi dini dan rujukan yang tepat pada anak-anak dengan gangguan keterlambatan perkembangan sangatlah penting (James P. Guevara, Marsha Gerdes, Russell Localio, Yuanshung V. Huang, Jennifer Pinto-Martin, Cynthia S. Minkovitz, Diane Hsu, Lara Kyriakou, Sofia Baglivo, Jane Kavanagh 2013).

Pemerintah Indonesia, dalam PMK no 66 Tahun 2015 Pasal 6 ayat 2 menegaskan perihal stimulasi, deteksi dini, dan intervensi gangguan tumbuh kembang anak (Kemenkes RI 2014). Salah satu instrumen SDIDTK ini adalah Kuesioner Pra Skrining Perkembangan (KPSP). KPSP ini merupakan instrumen yang digunakan sebagai intervensi awal dalam memantau perkembangan anak apakah sesuai dengan usia anak, meragukan atau bahkan terdapat penyimpangan (Kemenkes RI 2016).

Pemantauan tumbuh kembang merupakan salah satu kewenangan Bidan. STIKes Muhammadiyah Ciamis yang merupakan salah satu institusi pendidikan kesehatan di Jawa Barat memiliki program studi pencetak ahli madya kebidanan. Pembinaan program deteksi tumbuh kembang ini ada pada mata kuliah Asuhan Neonatus, Bayi dan Balita yang mempelajari bahasan tentang pengisian KPSP (Prodi D3 Kebidanan STIKes Muhammadiyah Ciamis 2019).

Beberapa penelitian menunjukkan hasil penggunaan aplikasi deteksi dini pertumbuhan dan perkembangan anak terbukti efektif dan efisien untuk mempermudah Bidan/petugas dalam pemantauan tumbuh kembang (Apriningrum, Carudin, and Rahayu 2018; Windiyani, Sundari, and Nurdianti 2019).

Pada penyampaian pesan proses pembelajaran diperlukan perantara agar value dan transfer of knowledge dapat tercapai dengan tepat pada sasarannya. Perantara tersebut merupakan media dan sumber-sumber belajar yang sangat menunjang dan memengaruhi keberhasilan belajarnya. Selama ini pengisian KPSP dalam proses pembelajaran dilakukan secara manual/konvensional dari lembaran kertas formulir kuesioner sesuai dengan usia anak (Mustofa Abi Hamid, Rahmi Ramdhani, et al., 2020). Berdasar permasalahan tersebut ditemukan suatu gagasan baru untuk memudahkan mahasiswa dalam pengisian KPSP, yaitu pembuatan sistem aplikasi berbasis android yang berisi tentang KPSP dan dapat dipasang dalam smartphone.

\section{Metode}

Penelitian ini merupakan penelitian pengembangan dengan mengembangkan aplikasi KPSP berbasis android untuk memudahkan mahasiswa dalam proses pembelajaran. Desain penelitian ini menggunakan research and development (R\&D) yaitu metode penelitian yang digunakan untuk menghasilkan produk tertentu dan menguji keefektifan produk tertentu (Hanafi 2017; Saputro 2017).

Proses penilaian dari subjek/pengguna aplikasi KPSP ini menggunakan kuesioner baku dari User Experience Questionnaire (UEQ) (Martin Schrepp, Andreas Hinderks 2018; Santoso et al. 2016), pengalaman pengguna diukur berdasarkan 26 item yang terdiri dari enam komponen, diantaranya:

1. Daya Tarik (attractiveness)

Poin ini merupakan kesan secara umum yang didapatkan dari pengguna. Penilaian untuk komponen ini adalah: mengganggu/menyenangkan, baik/buruk, tidak menyenangkan/menyenangkan, menarik/tidak menarik, ramah/tidak ramah,

2. Kejelasan (perspicuity)

Poin ini merupakan pertanyaan apakah mudah untuk memahami penggunaan produk/aplikasinya. Penilaian komponen ini adalah: tidak dimengerti/mengerti, mudah untuk dipelajari/sulit untuk dipelajari, rumit/mudah, jelas/membingungkan,

3. Efisiensi (efficiency)

Poin ini merupakan pertanyaan apakah memungkinkan produk/aplikasi ini digunakan secara cepat dan efisien. Penilaian komponen ini adalah: cepat/lambat, tidak efisien/efisien, tidak praktis/praktis, terorganisir/berantakan,

4. Ketepatan (dependability)

Poin ini merupakan pertanyaan apakah pengguna/subjek merasa mengendalikan interaksi. Penilaian pada poin ini adalah: tak terduga/diprediksi, obstruktif/mendukung, aman/tidak aman, memenuhi harapan/tidak memenuhi harapan,

5. Stimulasi (stimulation)

Poin ini merupakan pertanyaan pengguna tertarik menggunakan produk/aplikasi dan apakah pengguna tertarik untuk menggunakan produk/aplikasi lebih lanjut. Penilaian pada poin ini adalah: berharga/ rendah, membosankan/ 
meninggalkan, tidak menarik/ menarik, memotivasi/ menghilangkan motivasi.

\section{Kebaruan (novelty)}

Poin ini merupakan pertanyaan apakah aplikasi/produk inovatif dan kreatif juga apakah aplikasi/produk menarik perhatian pengguna/subjek. Penilaian pada poin ini adalah: kreatif/membosankan, inventif konvensional, biasa/terdepan, konservatif/inovatif.

Reliabilitas dan validitas dari skala UEQ telah diselidiki sebelumnya dalam beberapa penelitian (dalam 11 usability test dengan jumlah total 144 peserta dan survei online dengan 722 peserta). Studi menunjukkan bahwa reliabilitas dari UEQ cukup tinggi dengan menggunakan koefisien Cronbach-Alpha untuk estimasi konsistensi internal. Selain itu, hasil dari beberapa penelitian menunjukkan skala validitas yang baik. Setiap butir dari kuesioner diwujudkan sebagai diferensial semantik, yaitu setiap butirnya terdiri dari sepasang istilah dengan makna berlawanan (contoh: menyusahkan - menyenangkan). Hasil akhir dari UEQ digambarkan dalam grafik benchmark yang menunjukkan kualitas dari produk ke dalam lima kategori yaitu: excellent, good, above average, below average, dan bad.

Setiap komponen memiliki item yang menggunakan skala (1 sampai 7 ) dengan penilaian dari -3 hingga +3 . Sehingga, -3 mewakili jawaban paling negatif, 0 jawaban netral, dan +3 jawaban paling positif. Nilai skala di atas +1 menunjukkan kesan positif dari pengguna mengenai skala tersebut, nilai di bawah -1 menunjukkan kesan negatif (Santoso et al. 2016).

Produk tertentu dapat dihasilkan menggunakan penelitian yang bersifat analisis kebutuhan dan untuk menguji keefektifan produk tersebut supaya dapat berfungsi di masyarakat luas. Instrumen penelitian berupa kuesioner untuk uji coba aplikasi. Jumlah populasi sebanyak 59 orang mahasiswa Prodi D3 Kebidanan Semester IV dan VI sehingga seluruh mahasiswa dijadikan sebagai sampel (total sampling).

Alat dan bahan yang digunakan:

\section{Hardware}

a. PC; Processor: Intel Core i7-7700 3.60GHZ x4, RAM: $11.6 \mathrm{~GB}$, hard drives: $1240 \mathrm{~GB}$, graphic card: Intel HD 630

b. Smartphone; CPU: Quad-core $1.4 \mathrm{GHz}$ Cortex-A53, RAM: 2GB, ROM: 16GB
2. Software

a. PC; Linux Mint 20 Cinnamon, Android Studio 4.1, Open JDK 8

b. Smartphone: android oreo 8.1

Pengembangan aplikasi ini secara terstruktur dengan menggunakan metode waterfall pada tahapan software development life cycle (SDLC). Pada tahap ini dilakukan:

1. Requirements dan analysis

Tahapan pengumpulan kebutuhan dan analisa kebutuhan aplikasi/sistem yang akan dikembangkan.

2. Design

Tahapan pembuatan desain aplikasi/sistem sesuai dengan kebutuhan yang teridentifikasi pada tahapan analisa kebutuhan.

3. Pengujian Sistem

Tahapan dilakukannya tes uji sistem/aplikasi secara menyeluruh kepada mahasiswa untuk mengetahui apakah sudah sesuai dengan kebutuhan atau masih ditemukannya kekurangan pada proses skrining. Apabila ditemukan kekurangan atau ketidaksesuaian sistem, maka akan dilakukan revisi pada aplikasi/sistem tersebut.

Pengujian ini dilakukan kepada sampel dan diuji menggunakan kuesioner baku dari User Experience Questionnaire (UEQ).

4. Implement

Pada tahap ini aplikasi/sistem sudah digunakan dengan melakukan instalasi pada perangkat smartphone berbasis android.

5. Perawatan

Tahapan pengelolaan aplikasi/sistem agar selalu optimal dan memenuhi kebutuhan pengguna, pada tahap ini juga bisa terjadi revisi jika diperlukan sesuai dengan kebutuhan

Penelitian ini telah mengikuti prosedural uji kelayakan etik dari Komisi Etik Penelitian Kesehatan STIKes Muhammadiyah Gombong dengan No. 424.6/II.3.AU/F/KEPK/VI/2021.

\section{Hasil dan Pembahasan}

Hasil dari penilaian aplikasi Kuesioner Pra Skrining Perkembangan (KPSP) yang dilakukan peneliti menggunakan metode UEQ dengan kuesioner yang berisi 26 pertanyaan yang diberikan kepada responden yang terdiri dari mahasiswi Prodi D3 Kebidanan STIKes Muhammadiyah Ciamis sebanyak 59 orang. 
Tabel 1. Kategori UEQ

\begin{tabular}{|c|c|c|c|c|c|c|}
\hline \multirow[b]{2}{*}{ No } & \multirow[b]{2}{*}{ Aspek } & \multicolumn{5}{|c|}{ Kategori } \\
\hline & & Excellent & Good & $\begin{array}{c}\text { Above } \\
\text { average }\end{array}$ & $\begin{array}{c}\text { Below } \\
\text { average }\end{array}$ & Bad \\
\hline 1. & $\begin{array}{l}\text { Daya } \\
\text { Tarik }\end{array}$ & $>1.75$ & $\begin{array}{c}> \\
1.52\end{array}$ & $>1.17$ & $>0.70$ & $\leq 0.70$ \\
\hline 2. & Kejelasan & $>1.90$ & $\begin{array}{c}> \\
1.56\end{array}$ & $>1.08$ & $>0.64$ & $\leq 0.64$ \\
\hline 3. & Efisiensi & $>1.78$ & $\begin{array}{c}> \\
1.47\end{array}$ & $>0.98$ & $>0.54$ & $\leq 0.54$ \\
\hline 4. & Ketepatan & $>1.65$ & $\begin{array}{c}> \\
1.48\end{array}$ & $>1.14$ & $>0.78$ & $\leq 0.78$ \\
\hline 5. & Stimulasi & $>1.55$ & $\stackrel{>}{1.31}$ & $>0.99$ & $>0.50$ & $\leq 0.50$ \\
\hline 6. & Kebaruan & $>1.40$ & $\begin{array}{c}> \\
1.05\end{array}$ & $>0.71$ & $>0.30$ & $\leq 0.30$ \\
\hline
\end{tabular}

Masing-masing pertanyaan memiliki skala 1 - 7 pada setiap butir pertanyaan yang terdiri dari pasangan semantic diferensial yaitu pasangan butir yang berlawanan makna yang dapat merepresentasikan produk/aplikasi (Tabel 1.).

Berdasarkan jawaban dari 59 responden (Tabel 2.), setiap pertanyaan dilakukan penghitungan mean, varian, dan standar deviasinya. Masing-masing pertanyaan diberikan kode warna sesuai dengan kelompoknya yang terdiri dari daya tarik, efisiensi, kebaruan, kejelasan, dan stimulasi. Selanjutnya dilakukan sebaran penghitungan dalam bentuk tabel untuk bisa melihat jumlah nilai setiap komponennya.

Tabel 2. Sebaran Mean, Varian, dan Standar Deviasi Responden

\begin{tabular}{|c|c|c|c|c|c|c|c|}
\hline Item & Rerata & Variance & Std. Dev. & No. & Left & Right & Scale \\
\hline 1 & 술 1.5 & 0.7 & 0.9 & 59 & Menyusahkan & Menyenangkan & Daya Tarik \\
\hline 2 & 1.7 & 1.4 & 1.2 & 59 & Tak dapat dipahami & Dapat dipahami & Kejelasan \\
\hline 3 & -0.2 & 3.2 & 1.8 & 59 & Kreatif & Monoton & Kebaruan \\
\hline 4 & -0.1 & 4.1 & 2.0 & 59 & Mudah dipelajari & Sulit dipelajari & Kejelasan \\
\hline 5 & 0.0 & 5.8 & 2.4 & 59 & Bermanfaat & Kurang bermanfaat & Stimulasi \\
\hline 6 & 1.3 & 1.1 & 1.1 & 59 & Membosankan & Mengasyikan & Stimulasi \\
\hline 7 & 1.7 & 1.3 & 1.2 & 59 & Tidak menarik & Menarik & Stimulasi \\
\hline 8 & 1.4 & 1.4 & 1.2 & 59 & Tak dapat diprediksi & Dapat diprediksi & Ketepatan \\
\hline 9 & -0.1 & 3.5 & 1.9 & 59 & Cepat & Lambat & Efisiensi \\
\hline 10 & -0.5 & 2.7 & 1.6 & 59 & Berdaya cipta & Konvensional & Kebaruan \\
\hline 11 & 1.9 & 1.0 & 1.0 & 59 & Menghalangi & Mendukung & Ketepatan \\
\hline 12 & 0.3 & 5.0 & 2.2 & 59 & Baik & Buruk & Daya Tarik \\
\hline 13 & 1.8 & 1.5 & 1.2 & 59 & Rumit & Sederhana & Kejelasan \\
\hline 14 & 1.6 & 0.9 & 1.0 & 59 & Tidak disukai & Menggembirakan & Daya Tarik \\
\hline 15 & 1.4 & 1.4 & 1.2 & 59 & Lazim & Terdepan & Kebaruan \\
\hline 16 & 1.7 & 1.2 & 1.1 & 59 & Tidak nyaman & Nyaman & Daya Tarik \\
\hline 17 & 0.1 & 4.7 & 2.2 & 59 & Aman & Tidak aman & Ketepatan \\
\hline 18 & 0.2 & 4.8 & 2.2 & 59 & Memotivasi & Tidak memotivasi & Stimulasi \\
\hline 19 & 0.0 & 3.5 & 1.9 & 59 & Memenuhi ekspektasi & Tidak memenuhi ekspektasi & Ketepatan \\
\hline 20 & 1.6 & 1.2 & 1.1 & 59 & Tidak efisien & Efisien & Efisiensi \\
\hline 21 & -0.1 & 2.0 & 2.0 & 59 & Jelas & Membingungkan & Kejelasan \\
\hline 22 & 1.8 & 1.5 & 1.2 & 59 & Tidak praktis & Praktis & Efisiensi \\
\hline 23 & 0.0 & 3.9 & 2.0 & 59 & Terorganisasi & Berantakan & Efisiensi \\
\hline 24 & -0.1 & 3.1 & 1.7 & 59 & Atraktif & Tidak atraktif & Daya Tarik \\
\hline 25 & 0.0 & 4.4 & 2.1 & 59 & Ramah pengguna & Tidak ramah pengguna & Daya Tarik \\
\hline 26 & 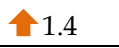 & 1.8 & 1.3 & 59 & Konservatif & Inovatif & Kebaruan \\
\hline
\end{tabular}

Tabel 3. Sebaran Mean dan Varian Komponen UEQ

\begin{tabular}{|c|c|c|}
\hline \multicolumn{3}{|c|}{ UEQ Scales (Mean and Variance) } \\
\hline Daya Tarik & 0.828 & 1.05 \\
\hline Kejelasan & 0.847 & 1.08 \\
\hline Efisiensi & 0.839 & 1.12 \\
\hline Ketepatan & 0.843 & 1.01 \\
\hline Stimulasi & 0.763 & 1.54 \\
\hline Kebaruan & 0.542 & 0.72 \\
\hline
\end{tabular}

Nilai rata-rata $>0.8$ mewakili evaluasi positif terhadap produk/aplikasi (tanda panah berwarna hijau arah atas), nilai rata-rata $<-0.8$ mewakili evaluasi negatif (tanda panah berwarna merah arah bawah), dan untuk nilai rata-rata antara -0.8 sampai 0.8 mewakili nilai netral (tanda panah berwarna kuning arah kanan).

Berdasarkan tabel 3, terdapat empat komponen yang bernilai positif dari produk/aplikasi KPSP menurut jawaban dari responden diantaranya adalah daya tarik, kejelasan, efisiensi, dan ketepatan. Sedangkan komponen stimulasi dan kebaruan bernilai netral. 


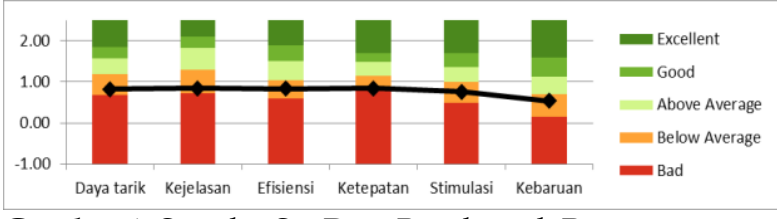

Gambar 1. Standar Set Data Benchmark Pengguna

Hasil sebaran rata-rata membantu analisa selanjutnya untuk menentukkan set data benchmark sebagai perbandingan produk aplikasi Kuesioner Pra Skrining Perkembangan (KPSP) dengan 468 produk kumpulan dari set data benchmark. Set data benchmark merupakan kumpulan data 21175 orang dari 468 penelitian mengenai produk yang berbeda (tidak hanya aplikasi KPSP) (Santoso et al. 2016; Schrepp, M.; Hinderks, A. \& Thomaschewski 2017).

Tabel 4. Hasil Set Data Benchmark Responden

\begin{tabular}{lcc}
\hline \multicolumn{1}{c}{ Scale } & Mean & $\begin{array}{c}\text { Comparison to } \\
\text { benchmark }\end{array}$ \\
\hline Daya Tarik & 0.83 & Below average \\
\hline Kejelasan & 0.85 & Below average \\
\hline Efisiensi & 0.84 & Below average \\
\hline Ketepatan & 0.84 & Below average \\
\hline Stimulasi & 0.76 & Below average \\
\hline Kebaruan & 0.54 & Below average \\
\hline
\end{tabular}

Berdasarkan tabel tersebut disimpulkan, komponen penilaian aplikasi KPSP oleh responden (pengguna/mahasiswa) seluruhnya masih di bawah rata-rata Berdasarkan perbandingan dari keseluruhan produk yang diujikan melalui User Experience Questionnaire (UEQ) (Díaz-Oreiro et al. 2019). Peneliti melihat berbagai keterbatasan dari pembuatan hingga pengujian aplikasi KPSP ini.

Statistik data menunjukkan interpretasi seluruh komponen 50\% hasil yang baik/memuaskan dan lainnya tidak memuaskan. Hal ini disebabkan karena penilaian aplikasi ini tidak hanya dilakukan oleh responden yang menjadi sasaran peneliti saja namun juga statistik nilai dibandingkan dengan aplikasi lainnya yang jauh lebih besar dari aplikasi KPSP ini (Schrepp, Martin; Hinderks, Andreas; Thomaschewski 2017), juga jumlah responden yang digunakan merupakan skala kecil (hanya 59 pengguna).

Penilaian secara objektif aplikasi KPSP dengan 59 responden ini bisa dilihat pada tabel 3 , komponen yang bernilai positif terdiri dari daya tarik, kejelasan, efisiensi, dan ketepatan. Sedangkan untuk stimulasi dan kebaruan bernilai netral.

Komponen stimulasi menggali seberapa mungkin pengguna menggunakan kembali aplikasi KPSP ini secara berkelanjutan, peneliti dapat meyakinkan aplikasi KPSP ini digunakan secara berkelanjutan karena proses skiring untuk anak akan terus dipelajari dan digunakan sesuai dengan kompetensi untuk ahli madya kebidanan dalam Undang-Undang No. 4 tentang Kebidanan di Indonesia (Undang-Undang RI No 4 2019) dan juga kurikulum Prodi D3 Kebidanan di Indonesia.

Namun tentu peneliti perlu memperbaiki aplikasi KPSP ini sesuai dengan hasil dari tabel 3 tentang aspek kebaruan aplikasi, keterbatasan tampilan (user interface), isi, dan bahasa aplikasi ini perlu dimodifikasi agar lebih interaktif dan mutakhir sesuai dengan minat pengguna.

\section{Simpulan dan Saran}

Aplikasi KPSP perlu perbaikan pada aspek kebaruan, keterbatasan tampilan (user interface), isi, dan bahasa aplikasi ini perlu dimodifikasi agar lebih interaktif dan mutakhir sesuai dengan minat pengguna.

Untuk penelitian selanjutnya, disarankan perbaikan pada tampilan untuk pengguna dan diujikan pada pengguna yang lebih luas tidak hanya mahasiswa untuk proses pembelajaran tetapi untuk Bidan pada pelayanan mandiri maupun komunitas.

\section{Ucapan Terima Kasih}

Terima kasih kepada Kemdikbudristek yang telah mendanai seluruh rangkaian penelitian ini melalui program Hibah Penelitian 2021.

\section{Daftar Pustaka}

Apriningrum, Nelly, Carudin Carudin, and Maria Alia Rahayu. 2018. "Rancang Bangun Aplikasi KPSP Berbasis Android Bagi Anak Balita Sampai Pra Sekolah Di Kabupaten Karawang." Jurnal Sistem Dan Teknologi Informasi (JUSTIN) 6(4):200. doi: 10.26418/justin.v6i4.27385.

Díaz-Oreiro, López, Quesada, and Guerrero. 2019. "Standardized Questionnaires for User Experience Evaluation: A Systematic Literature Review." Proceedings 31(1):14. doi: 10.3390/ proceedings2019031014.

Hanafi. 2017. "Konsep Penelitian R \& D Dalam Bidang Pendidikan." Saintifika Islamica: Jurnal Kajian Keislaman 4(2):129-50.

James P. Guevara, Marsha Gerdes, Russell Localio, Yuanshung V. Huang, Jennifer PintoMartin, Cynthia S. Minkovitz, Diane Hsu, Lara Kyriakou, Sofia Baglivo, Jane 
Kavanagh, Susmita Pati. 2013. "Effectiveness of Developmental Screening in an Urban Setting." Pediatrics 131 (1)(30-37). doi: 10.1542/peds.2012-0765.

Kemenkes RI. 2014. Peraturan Kementerian Kesehatan RI Nomor 66 Tahun 2014.

Kemenkes RI. 2016. SURAT Edaran Nomor HK.03.03/V/0595/2016 tentang Pemberian Tablet Tambah Darah.

Martin Schrepp, Andreas Hinderks, Jörg Thomaschewski. 2018. "User Experience Questionnaire (UEQ)." Retrieved (https://www.ueqonline.org/).

Mustofa Abi Hamid, Rahmi Ramdhani, Masrul Juliana, Meilani Safitri, Muhammad Muisarif Jamaludin, Janner Simarmata. 2020. Media Pembelajaran. Medan: Yayasan Kita Menulis.

Prodi D3 Kebidanan STIKes Muhammadiyah Ciamis. 2019. Kurikulum Prodi D3 Kebidanan Tahun 2018. Ciamis.

Santoso, Harry B., Martin Schrepp, R. Yugo Kartono Isal, Andika Yudha Utomo, and Bilih Priyogi. 2016. "Measuring User Experience of the Student-
Centered E-Learning Environment." Journal of Educators Online 13(1):1-79.

Saputro, Budiyono. 2017. Manajemen Penelitian Pengembangan (Research \& Development) Bagi Penyusun. Yogyakarta: IKAPI.

Schrepp, M.; Hinderks, A. \& Thomaschewski, J. 2017. "Construction of a Benchmark for the User Experience Questionnaire (UEQ). International Journal." International Journal of Interactive Multimedia and Artificial Intelligence $4(4): 40-44$.

Schrepp, Martin; Hinderks, Andreas; Thomaschewski, Jörg. 2017. “Design and Evaluation of a Short Version of the User Experience Questionnaire (UEQS)." IJIMAI 4(6):103-108.

Windiyani, Winda, Sri Wahyuni Sundari, and Dewi Nurdianti. 2019. "Rancang Bangun Aplikasi Stimulasi Deteksi Intervensi Dini Tumbuh Kembang Anak (SDIDTK) Bagi Bidan Di Posyandu." Jurnal Riset Kebidanan Indonesia 3(2):87-94. doi: 10.32536/jrki.v3i2.59. 